\title{
Factors Affecting Innovative Work Behavior: Mediating Role of Knowledge Sharing and Job Crafting
}

\author{
Achmad Sani SUPRIYANTO ${ }^{1}$, Agus Eko SUJIANTO ${ }^{2}$, Vivin Maharani EKOWATI ${ }^{3}$
}

Received: August 01, 2020 Revised: September 30, 2020 Accepted: October 15, 2020

\begin{abstract}
This study aimed to investigate the influence of spiritual leadership on innovative work behavior and the effect of knowledge sharing on job crafting. Furthermore, the roles of knowledge sharing as a mediator for the impact of spiritual leadership on innovative work behavior, and job crafting as a mediator for the relationship between variables, were also examined. This research employed quantitative analysis, including the PLS-SEM approach; SMART-PLS, a measurement and structural equation model was employed to explain the relationship between variables, and the effect of mediation. The population study consisted of all lecturers at the Faculty of Economics and Faculty of Economics and Business at the PTKIN in East Java, Indonesia, comprising 220 randomly-selected samples. The result showed spiritual leadership does not directly influence innovative work behavior, while knowledge sharing directly affects job crafting. The findings indicated knowledge sharing mediates the impact of spiritual leadership on innovative work behavior, and the role of job crafting as a mediator for the relationship between variables was accepted. Therefore, this research confirms a positive influence of knowledge sharing on job crafting, and indicates both factors play an important role in mediating between variables, and are important for lecturers' innovative work behavior.
\end{abstract}

Keywords: Spiritual Leadership, Knowledge Sharing, Job Crafting, Innovative Work Behavior, Statistical Indicators

JEL Classification Code: J24, M12, M14, M54

\section{Introduction}

The intense competition between tertiary institutions, regulatory changes, and quality assurance standardization by the Directorate General of Higher Education, Ministry of Education and Culture of Indonesia (DIKTI), demands an improvement in quality of universities through innovative upgrades to educational management.

${ }^{1}$ First Author and Corresponding Author. Professor, Department of Management, Faculty of Economics, State Islamic University of Maulana Malik Ibrahim, Malang, Indonesia [Postal Address: Jl. Gajayana No.50, Dinoyo, Kec. Lowokwaru, Kota Malang, Jawa Timur 65144, Indonesia] Email: achmad_sani72@yahoo.com

${ }^{2}$ Associate Professor, Faculty of Islamic Economic and Business, State Islamic Institute of Tulungangung, Indonesia.

Email: agusekosujianto@gmail.com

${ }^{3}$ Associate Professor, Department of Management, Faculty of Economics, State Islamic University of Maulana Malik Ibrahim, Malang, Indonesia. Email: vivien.maharani@yahoo.com

(c) Copyright: The Author(s)

This is an Open Access article distributed under the terms of the Creative Commons Attribution Non-Commercial License (https://creativecommons.org/licenses/by-nc/4.0/) which permits unrestricted non-commercial use, distribution, and reproduction in any medium, provided the original work is properly cited.
According to Wibowo (2016), ingenious steps required to raise the quality of advanced education covers several aspects, including legality, value management, accountability, and stakeholder perceptions. These efforts ensure continuity and standardization, and the improvements in quality and image is attained by input advancement, selection of qualified incoming students, enhancement in learning processes, and inventive field research and community service. In addition, a measurement for assessment is accreditation, and based on Government Regulation Number 32 of 2013 as an Amendment to Government Regulation Number 19 of 2005 on National Education Standards, this is employed to assess the practicability of programs and academic units using predetermined criteria. Therefore, the tool ensures quality of schools and measures the readiness of a university to carry out the educational process. Furthermore, evaluation, accreditation and certification are applied to adjust education quality assurance and control to national standard.

The implementation of innovative work behavior is necessary due to the changing environment of higher education, globalization and increasing competition between corporations (Woods et al., 2017). This positive, constructive and helpful social behavior portrays the added value of 
employees (Supriyanto, 2019), and is important for the survival of organizations (Hon \& Lui, 2016; Kim \& Koong, 2018; Li \& Hsu, 2016). Furthermore, the attitude is prevalent in customer service-focused organizations, including universities, where there is a need to stay informed about technological changes and for lecturers to be consistently innovative. Therefore, to improve overall quality and performance, higher education motivates lecturers towards generation and implementation of new ideas (Edghiem \& Mouzughi, 2017; Li \& Hsu, 2016).

Leadership is a part of management function and plays an important role to improve the quality (Adeel et al., 2019). Furthermore, this has the potential to promote innovative work behavior by employee motivation, creation of conducive atmosphere, creativity and innovation development, leading to competitive advantages for organizations (Patiar \& Wang, 2016; Schuckert et al., 2018; Supriyanto et al., 2020). In addition, leaders have the ability to adapt to environmental changes, stimulate intrinsic motivation and influence subordinates creativity by providing resources and a favorable work environment (Padayachee, 2009; William et al., 2017; Paais \& Pattiruhu, 2020)).

Various theories debate the right leadership style to foster innovative work behavior among employees, and previous research emphasizes spiritual leadership as important (Supriyanto, 2019; Wang et al., 2019). Moreover, this style is suitable for organizations adapting constantly to environmental changes, and involves not only intelligence and leadership skills, but also shaping of personal and others characters and morals by continually upholding spiritual values including truth, honesty, integrity, credibility, wisdom, and compassion. (Fry, et al., 2011; Sani et al., 2016). Several conducted research on leadership were focused on organizational climate (Stachowicz-Stanusch \& Simha, 2013); organizational justice (Yang et al., 2013); employee effectiveness (Wang et al., 2017); and innovative work behavior (Afsar et al., 2019). Contreras et al. (2017) postulates an indirect influence of leadership on innovative work behavior through organizational climate. However, while spiritual leadership is very important to increase organizational effectiveness, there are differences between theory and practice in reality (Ather \& Sobhani, 2007).

Generally, tertiary institutions are customer-oriented, and therefore, integration of knowledge and creativity by the academic community is necessary to improve the image of the university. To achieve this, effort is made to implement proactive work behavior through changing and reshaping tasks to keep jobs challenging and motivate employees to execute, known as job crafting (Patiar \& Wang, 2016); (Kim $\&$ Koong, 2018). This views employees as passive recipients of organizational design, and proactively modifies jobs to suit individual preferences, therefore evoking a feeling of suitability for the job. Consequently, the underlying factor is a fundamental desire in workers to find positive meaning and to build a confident self-identity in the organization (Sengkey \& Meiyanto, 2016).

Research on job crafting has increased rapidly over the last decade and received large attention in recent job design literature. However, there is confusion on ways to develop the practice despite the positive influence on the lives and welfare of employees, and workplace prosperity. Insufficient literature exploring exhaustively the association between leader behavior and job crafting exists (Rudolph et al., 2017; Wang et al., 2017). However, recent studies show resulting increase in work engagement, creativity, performance (Demerouti et al., 2015; Slemp \& Vella-Brodrick, 2014; Van Wingerden et al., 2017; Nguyen et al., 2019), and innovative work behavior (Devloo et al., 2015; Tangaraja et al., 2015). Therefore, job crafting mediates the way spiritual leadership affects innovative work behavior.

Lee and Song (2018) posited an improvement in job crafting through intrinsic motivation and knowledge sharing. Furthermore, Lin (2007) highlighted the accommodation of spiritual leadership influence on innovative work behavior by employee knowledge sharing, where a proportion of individuals share information with colleagues. The sharing of information and knowledge results in innovation (Ritala et al., 2015; Almuhlim, 2020), and therefore among employees, bridges the influence of spiritual leadership on innovative work behavior.

The various contradictory research provide a gap for this study to examine the influence of spiritual leadership on employee behavior directly, and through mediating variables, comprising knowledge sharing and job crafting. The addition of these variables is believed to enable a bridging of the gap between leadership and employee behavior in line with the findings by Van Wingerden et al. (2017); Wang et al. (2017); (Ritala et al., 2015) of a resulting innovative work behavior. Therefore, this study aims to analyze the influence of spiritual leadership on innovative work behavior, the effect of knowledge sharing on job crafting, and the role of knowledge sharing and job crafting as mediators for the influence of spiritual leadership on innovative work behavior.

\section{Literature Review and Hypotheses}

Reave (2005) defined spiritual leadership as an observable phenomenon arising when a person in a leadership position embodies spiritual values including integrity, honesty, humility, and creates an example capable of trust, reliance and admiration.

Furthermore, innovative work behavior refers to the ability of an individual to create new ideas while working (Birdi et al., 2016). According to Janssen (2000), this results from comprehensive set of behaviors related to idea creation and implementation. Axtell et al. (2000) defines the behavior 
as an increased ability for developing new ideas related to a number of organizational jobs, and is aimed as a set of tools for progress (Jong \& Hartog, 2007), being a result of individuals facing problems and generating solutions (Afsar et al., 2017; Akram et al., 2018). Also, spiritual leadership is attentive, and motivates increased creativity in employees through innovative work behavior (Afsar et al., 2019). Therefore, the research hypothesis based on the described theoretical and empirical studies is:

H1: A better spiritual leadership increases innovative work behavior

Knowledge sharing reflects a social interaction culture involving employee knowledge, experiences, and skills, exchanged across departments or organizations (Lin, 2007). In addition, this behavior comprises information exchange and contribution of ideas relevant to the task (Edwards et al., 2017), and impacts organizational innovation (Kim \& Lee (2013). This is because to complete innovative tasks, employees need to continually gain benefit from the knowledge, skills and work experience existing in the organization. Therefore, to generate new ideas and thoughts useful for organizational development, leaders are to encourage the practice of sharing knowledge among employees, groups, and within the organization (Tuan, 2017; Liao et al., 2018).

Job crafting is viewed as a change to meaningful, interesting, and satisfying work, initiated by employees (Demerouti, 2014). In addition, this is characterized by searching for job opportunities and reducing job demands endangering the organizational development (Petrou et al., 2015). The research hypothesis based on the described theoretical and empirical studies is:

H2: An increased knowledge sharing improves job crafting behavior

Padayachee (2009) indicated the need for leaders to nurture and respect spiritual needs by effectively applying practices, to prevent unhealthy consequences arising for individuals, organizations and society. Furthermore, good leaders are required to integrate spirituality with five leadership practices, comprising challenging the process, inspiring a common vision, enabling others to act, setting an example, and giving encouragement.

Lin (2007) affirmed the accommodation of spiritual leadership influence on innovative work behavior by employee knowledge sharing, where a proportion of individuals share information with colleagues, resulting in innovation (Ritala et al., 2015). Furthermore, these leaders have the ability to articulate organizational vision with individual goals, and increase inspirational motivation among followers (Bednall et al., 2018). Therefore, the assumption is spiritual leaders are capable of inspiring employees to engage in innovative work behavior by developing a sense of belonging to the organization, enabling ease to initiate and implement the change process. The research hypothesis based on the described theoretical and empirical studies is:

H3: Knowledge sharing mediates the influence of knowledge sharing on innovative work behaviors

Job crafting includes changing and reshaping of tasks to keep jobs challenging, and motivate execution by employees (Patiar \& Wang, 2016; Kim \& Koong, 2018). Furthermore, the basic underlying premise is an active ability of employees to coordinate tasks based on experience, by making changes to jobs. Leaders play an important role in inspiring employees through the development of job crafting (Petrou et al., 2012), causing a change in work method, better performance and task enjoyment. Therefore, an increased involvement stimulates creation of new ideas in carrying out work (Kim \& Koong, 2018). The research hypothesis based on the described theoretical and empirical studies is:

H4: job crafting mediates the influence of knowledge sharing on innovative work behavior.

\section{Research Methods and Materials}

The data collection technique used was questionnaire, provided to all lecturers of Islamic Higher Education in East Java. In addition, the study population includes all lecturers at the Faculty of Economics and Islamic Business from Islamic Universities in East Java, with a total of 220. Data collection involved the distribution of questionnaire to all respondents. spiritual leadership refers to Yusof (2011), measurement of innovative work behavior variables refers to Kim and Lee (2013), Knowledge sharing refers to Afsar et al. (2019), job crafting refers to (Tims et al., 2012); Afsar et al., 2019). The measure used to evaluate the variables was the Likert scale, weighed according to the items, with a range of 1 to 5 (Sekaran, 2003).

This research also employed quantitative analysis, including PLS-SEM approach, because the concept was to test the modified results of several research models to provide an overview of the variables studied (Garson, 2016). The variables and constructs measurement criteria were based on conditions, including the AVE value $>0.50$ (Hair et al., 2014; Supriyanto et al., 2020) and the composite reliability value (CR> 0.6) (Chin, 1998; Supriyanto \& Ekowati, 2020). Also, the main constituents of variables are measurement of Cronbach's alpha value $>0.5$ (Chin, 1998). 


\section{Results and Discussion}

\subsection{Statistical calculation results}

This research stage is to examine the relationship between variables using SMART-PLS, as well as measurement and structural equation models. Furthermore, the reliability test result for each variable, comprising spiritual leadership, innovative work behavior, knowledge sharing and job crafting, had a higher Cronbach's alpha value compared to the cut off point 0.60 . Therefore, the variables are accepted internally, because Cronbach's alpha needs to be higher than $\alpha>0.60$ (Hair et al., 2014). However, the results of composite reliability are declared accurate, where the value is above 0.70 . the square root of average variance extracted ( $\sqrt{A V E}$ ) outcome for all the variables designed in this study to be greater than the correlation between latent types, therefore the instrument is declared to be valid. This also compares the square root of average variance extracted $(\sqrt{ } \mathrm{AVE})$ with 0.5 . Table 1 shows the results.

\subsection{Structural Equation Modeling}

SEM using PLS was performed to test hypotheses including direct and indirect or moderating effects.

\subsubsection{Direct Effects}

The results of the direct effects described in this study are shown in Table 2. The findings indicated that spiritual leadership did not influence innovative work behavior (path coefficient $=0.188, \mathrm{P}>0.000$ ), hence H1 was statistically rejected. Also, the relationship between knowledge sharing and job crafting was found to be positive and significant with (path coefficient $=0.415, \mathrm{p}<0.000$ ), therefore $\mathrm{H} 2$ was accepted.

\subsubsection{Mediating Effects}

This study investigates the mediating effect of knowledge sharing and job crafting. For the investigation, each relationship was tested using PLS path analysis. Interestingly, with knowledge sharing found to mediate the correlation between spiritual leadership and innovative work behavior, With the results $(\beta=0.192, p=0.027<0.000)$; therefore $\mathrm{H} 3$ is statistically accepted. Also, the relationship between spiritual leadership and innovative work behavior is reflected by job crafting, with an outcome of $\beta=0.176$, ( $p$ $=0.004<0.000$ ); hence H4 is statistically accepted. Table 3 shows a summary of the results.

Table 1: Results of Instrument Reliability Testing

\begin{tabular}{|l|c|c|c|c|}
\hline Variable & Cronbach's Alpha & Composite Reliability & AVE & VAVE \\
\hline Spiritual Leadership & 0.873 & 0,923 & 0,664 & 0,815 \\
\hline Knowledge sharing & 0.781 & 0,853 & 0,803 & 0,896 \\
\hline Job crafting & 0.827 & 0,894 & 0,584 & 0,764 \\
\hline IWB & 0.632 & 0,703 & 0,683 & 0,826 \\
\hline
\end{tabular}

Table 2: Hypothesis Testing Results for Direct Effect

\begin{tabular}{|l|c|c|c|c|c|}
\hline Independent Variable & Dependent Variable & Path Coefficient & t statistics & p-value & Description \\
\hline SL & IWB & 0,188 & 1,407 & 0,160 & Not significant \\
\hline KS & JC & 0,415 & 4,955 & 0,000 & Significant \\
\hline SL & KS & 0,793 & 19,286 & 0,000 & Significant \\
\hline SL & JC & 0,426 & 5,711 & 0,000 & Significant \\
\hline KS & IWB & 0,234 & 2,364 & 0,019 & Significant \\
\hline JC & IWB & 0,421 & 3,560 & 0,000 & Significant \\
\hline
\end{tabular}

Table 3: Hypothesis Testing Results for Indirect Effects

\begin{tabular}{|l|c|c|c|c|}
\hline Variable Relationships & Path Coefficient & $\mathbf{t}$ statistics & p-value & Description \\
\hline SL-KS-IWB & 0.192 & 2,229 & 0,027 & Significant \\
\hline SL-JC-IWB & 0.176 & 2,866 & 0,004 & Significant \\
\hline
\end{tabular}




\subsection{Discussion}

The path analysis on the inner model shows spiritual leadership has no direct influence on innovative work behavior, and this confirms Contreras et al. (2017) findings of an indirect effect through organizational climate. Furthermore, this affirms Jong and Hartog's (2007) discovery of leaders having an impact on employee innovation through deliberate actions aimed at stimulating the application of novel ideas to support performance. Supriyanto's (2019) supports the result indicating spiritual leadership does not directly increase innovative behavior. Therefore, leadership has the potential to promote innovative work behavior by employee motivation, creation of conducive atmosphere, and creativity and innovation development leading to competitive advantage for organizations (Patiar \& Wang, 2016; Schuckert et al., 2018).

However, the result is inconsistent with Wang et al. (2019) findings of innovative behavior being increased by leadership. Leadership plays no role because innovation emphasizes creativity, and improves performance by idea implementation. Furthermore, innovative work behavior is described as individual attitude aimed at achieving deliberate initiation and recognition (within work roles, groups or organizations) for ideas, processes, and products, and the IWB developed measure encourages creative thoughts. Purba (2009) declares this emphasizes existence of creative attitudes, and therefore, involves the process of changing from traditional to modern attitudes, or from unadvanced to advanced.

IWB is influenced by several factors, including task autonomy, learning opportunities, job involvement, employee motivation and emotional distress. Furthermore, a feeling of comfort with a job results in constant work involvement and freedom from emotional stress, and therefore a greater tendency for innovation (Spiegelaere et al., 2014). In addition, a response of high innovative behavior arises from valuing employees greatly, and is limited when the work done is less valued. The conclusion based on the social exchange theory is leader behavior influences employee attitude. According to Jong and Hartog (2007), employees vary in work performance or showing IWB, and tend to innovate to perform tasks correctly, but stop when judged to be good.

The path analysis on the inner model shows knowledge sharing significantly influences job crafting. This is consistent with Lin (2007) findings of increased innovative work behavior through employee knowledge sharing, where a proportion of individuals share information with colleagues, and results in innovation (Ritala et al., 2015). Therefore, the influence of spiritual leadership on innovative work behavior is bridged by sharing and exchanging information among employees, because others access sufficient information to generate and implement new ideas.
The research results are supported by Lee and Song (2018) discovery of an improvement in job crafting through intrinsic motivation and knowledge sharing. Furthermore, knowledge sharing reflects social interaction culture involving employee exchange of knowledge, experiences, and skills across departments or organizations (Lin, 2007), and impacts organizational innovation (Kim \& Lee (2013). This behavior involves communicating information and contributing ideas relevant to completing innovative tasks (Edwards et al., 2017). Therefore, to generate new useful ideas and thought, leaders are to encourage the practice of sharing knowledge among employees, groups, and within the organization (Tuan, 2017); Liao et al., 2018).

Job crafting considers employees as passive recipients of an organizational design, and proactively modifies jobs to suit individual preferences. Furthermore, performing this results in a feeling of job suitability in workers and ultimately being bound to the work. The underlying factor is the existence of a fundamental desire to find positive meaning in tasks and to build a positive self-identity in the organization (Sengkey \& Meiyanto, 2016).

The path analysis results for spiritual leadership, knowledge sharing and innovative work behavior show a path coefficient value of 0.192 , with a t-count value of $2.229>1.96$ and a significance of $0.027<0.05$. Therefore, the conclusion is knowledge sharing mediates the influence of spiritual leadership on innovative work behavior, and Afsar et al. (2019) corroborates this improvement in IWB by leadership. Similarly, Wang et al. (2019) highlighted an effect on knowledge sharing and innovative work behavior by spiritual leadership and this is supported by findings of William et al. (2017) stating the ability of leaders to adapt to environmental changes, stimulate intrinsic motivation and use personal knowledge to influence subordinates' creativity by providing resources and creating favorable work environment.

Knowledge sharing is a form of reflection measured by contribution, and the practices and norms increase innovative work behavior under transformational leaders (Mittal \& Dhar, 2015). Furthermore, this is viewed as a facilitator of the leadership role, and remains an important key utilized by leaders to direct innovation in employees.

Knowledge sharing is a set of behaviors involving information exchange, sharing, suggestion and contributions to relevant tasks between team members (Edwards et al., 2017). In addition, to complete innovative tasks, there is need for employees to continually gain benefit from the knowledge, skills and work experience existing within the organization. Therefore, to generate new ideas and thoughts useful for developing new opportunities leaders are to encourage the practice of sharing knowledge among employees, groups, and within workplaces (Tuan, 2017; Liao et al., 2018). 
The study findings support Lin (2007) to indicate influence of spiritual leadership on innovative work behavior is accommodated by employee knowledge sharing. Knowledge sharing refers to a proportion of individuals sharing information with colleagues, and results in innovation (Ritala et al., 2015). Therefore, this bridges the influence of spiritual leadership on innovative work behavior because others access sufficient information to generate and implement new ideas under spiritual leadership where individuals share knowledge.

The path analysis results for spiritual leadership, job crafting and innovative work behavior show a path coefficient value of 0.176 , with a t-count value of $2.866>1.96$ and a significance of $0.004<0.05$. Therefore, the conclusion is job crafting mediates the influence of spiritual leadership on innovative work behavior. Furthermore, the research results corroborate Supriyanto and Ekowati (2020) to find spiritual leadership as a process influencing subordinates by creativity and innovation development. Patiar and Wang (2016); Schuckert et al. (2018) found leadership has the potential for promoting innovative work behavior by employee motivation, creation of conducive atmosphere, and promotion of creativity and innovation, resulting in a competitive advantage for the organization. In addition, leadership influences organizational members activities by combining creativity and innovation, and beyond getting a position or power, involves a process of interaction and communication between leaders and subordinates. Therefore, a leader has the ability to work effectively and influence others using personal knowledge (William et al., 2017).

The research results affirms Afsar et al. (2019) discovery of IWB improving by leadership, and Contreras et al. (2017) supports an indirect effect of leadership on innovative work behavior through organizational climate. Furthermore, job crafting is viewed as a change to meaningful, interesting, and satisfying work initiated by employees (Demerouti, 2014) and is characterized by searching for job opportunities and reducing job demands endangering organizational development (Petrou et al., 2015). Leaders play an important role in inspiring employees through the development of job crafting (Petrou et al., 2012), causing a change in work method, better performance and task enjoyment. Therefore, an increased involvement stimulates creation of new ideas in work execution (Kim \& Koong, 2018). Also, leaders create active learning environments (Wang et al., 2017), and the work is made more attractive by giving lecturers autonomy and development time. The underlying premise of job crafting is the existence of a fundamental desire in employees to find positive meaning in work and to build a positive self-identity in the organization (Dutton et al., 2010).

\section{Conclusion}

Spiritual leadership does not directly influence innovative work behavior. Furthermore, leaders influence employee innovative behavior through deliberate actions aimed at stimulating the application of novel ideas to support performance. Therefore, leadership has the potential to promote innovative work behavior by employee motivation, creation of a conducive atmosphere, and creativity and innovation development, leading to competitive advantage for the organization. Also, knowledge sharing refers to a proportion of individuals sharing information with colleagues and results in access by others to sufficient information to generate and implement new ideas. The completion of innovative tasks in an organization requires continuously gaining benefit from the knowledge, skills and work experience present, and leaders are to encourage this practice to generate new ideas and thoughts necessary for organizational development. The leaders play an important role in inspiring employees through job crafting development, and this stimulates the creation of novel ideas in work execution.

\section{References}

Adeel, A., Arshad, M. A., Mahmood, A., \& Akhtar, S. (2019). The IOCB Influence of Spiritual Values on Employee's Helping Behavior: The Moderating Role Of Islamic Work Ethic. Journal of Management, Spirituality \& Religion, 16(3), 1-29. doi: 10.1080/14766086.2019.1572529.

Afsar, B., Badir, Y. F., Saeed, B. B., \& Hafeez, S. (2017). Transformational and Transactional Leadership and Employee's Entrepreneurial Behavior in Knowledge-Intensive Industries. The International Journal Of Human Resource Management, 28(2), 307-332. doi:10.1080/09585192.2016.1244893

Afsar, B., Masood, M., \& Umrani, W. A. (2019). The Role of Job Crafting and Knowledge Sharing on The Effect of Transformational Leadership on Innovative Work Behavior. Personnel Review, 48(5), 1186-1208. doi:10.1108/PR-04-20180133

Akram, T., Lei, S., Haider, M. J., \& Hussain, S. T. (2018). Exploring the Impact of Knowledge Sharing on the Innovative Work Behavior of Employees: A Study in China. International Business Research, 11(3), 186-199. doi:10.5539/Ibr.V11n3p186

Almuhlim, A. F. (2020). Link Knowledge Sharing To Innovative Work Behavior: The Role Of Psychological Empowerment. Journal of Asian Finance, Economics and Business, 7(9), 549560. doi: 10.13106/jafeb.2020.vol7.no9.549

Ather, S., \& Sobhani, F. (2007). Managerial Leadership: An Islamic Perspective. IIUC Studies, 4(1), 7-24. doi:10.3329/Iiucs. V4i0.2688 
Axtell, C., Holman, D., \& Wall, T. (2006). Promoting Innovation: A Change Study. Journal Of Organizational And Occupational Psychology, 79(3), 509-516. doi:10.1348/096317905X68240

Bednall, T. C., Rafferty, A. E., Shipton, H., Sanders, K., \& Jackson, C. J. (2018). Innovative Behaviour: How Much Transformational Leadership Do You Need? British Journal Of Management, 29(4), 796-816. doi: 10.1111/1467-8551.12275.

Birdi, K., Leach, D., \& Magadley, W. (2016). The Relationship of Individual Capabilities and Environmental Support with Different Facets of Designers' Innovative Behavior. Journal Of Product Innovation Management, 33(1), 19-35. doi:10.1111/ Jpim. 12250

Chin, W. (1998). The Partial Least Squares Approach To Structural Equation Modeling. Modern Methods For Business Research, 295(2), 295-336. doi:10.1016/J.Aap.2008.12.010

Contreras, F., Espinosa, J. C., Dornberger, U., \& Acosta, Y. A. C. (2017). Leadership And Employees' Innovative Work Behavior: Test Of A Mediation And Moderation Model. Asian Social Science, 13(9), 9-25. doi:10.5539/Ass.V13n9p9

Devloo, T., Anseel, F., De Beuckelaer, A., \& Salanova, M. (2015). Keep the Fire Burning: Reciprocal Gains of Basic Need Satisfaction, Intrinsic Motivation and Innovative Work Behavior. Europe Journal Work Organizational Psychology, 24, 491-504. doi: 10.1080/1359432X.2014.931326

Demerouti, E., Bakker, A. B., \& Gevers, J. M. (2015). Job Crafting and Extra-Role Behavior: The Role of Work Engagement and Flourishing. Journal of Vocational Behavior, 91, 87-96. doi:10.1016/J.Jvb.2015.09.001

Dutton, J. E., Roberts, L. M., \& Bednar, J. (2010). Pathways to Positive Identity Construction at Work: Four Types of Positive Identity and The Building of Social Resources. Academy Of Management Review, 35, 265-293. doi:10.5465/ AMR.2010.48463334

Edghiem, F., \& Mouzughi, Y. (2017). Knowledge-Advanced Innovative Behavior: A Hospitality service Perspective. InternationalJournalofContemporaryHospitalityManagement, 30(1), 197-216. doi:10.1108/IJCHM-04-2016-0200

Edwards, D., Cheng, M., Wong, I. A., Zhang, J., \& Wu, Q. (2017). Ambassadors Of Knowledge Sharing: CoProduced Travel Information Through Tourist-Local Social Media Exchange. International Journal of Contemporary Hospitality Management, 29(2), 690-708. doi: 10.1108/ IJCHM-10-2015-0607

Garson, G. D. (2016). Partial Least Square: Regression And Structural Equations Models. North Carolina State University, USA: School of Public \& International Affairs. Retrieved From Https:/Www.Smartpls.Com/Resources/Ebook_On_Pls-Sem. Pdf.

Fry, W., Hannah, S. T., Noel, M., \& Walumbwa, F. O. (2011). Impact Of Spirituality Leadership On Unit Performance. The Leadership Quarterly, 22, 259-270.

Hair, J. F., Henseler, J., Dijkstra, T. K., \& Sarstedt, M. (2014). Common Beliefs And Reality About Partial
Least Squares: Comments On Rönkkö And Evermann. Journal Organizational Research Method, 17(2), 182-209. doi:10.1177/1094428114526928

Hon, A. H., \& Lui, S. S. (2016). Employee Creativity and Innovation in Organizations: Review, Integration, And Future Directions for Hospitality Research. International Journal Of Contemporary Hospitality Management, 28(5), 862-885. doi:10.1108/IJCHM-09-2014-0454

Janssen, O. (2000). Job Demands, Perceptions of EffortReward Fairness, And Innovative Work Behavior, Journal of Occupational and Organizational Psychology, 73, 287-302. doi:10.1348/096317900167038

Jong, D. J., \& Hartog, D. D. (2007). How Leaders Influence Employees' Innovative Behavior. European Journal Of Innovation Management, 10(1), 41-64. doi: $10.1108 / 14601060710720546$

Kim, T. T., \& Lee, G. (2013). Hospitality Employee Knowledge Sharing Behaviors In The Relationship Between Goal Orientations And Service Innovative Behavior. International of Hospitality Management, 34(2), 324-337. doi: 10.1016/J. Ijhm.2013.04.009

Kim, H., Im, J., Qu, H., \& Koong, N. J. (2018). Antecedent And Consequences Of Job Crafting: An Organizational Level Approach. International Journal of Contemporary Hospitality Management, 30(3), 1863-1881. doi:10.1108/ IJCHM-01-2017-0040

Lee, J. W., \& Song, Y. J. (2018). Promoting Employee Job Crafting At Work: The Role Of Team Context And Motivation. Academy of Management Proceedings. 2018(1) doi:10.5465/ AMBPP.2018.15622abstract

Li, M., \& Hsu, C. H. (2016). A Review Of Employee Innovative Behavior In Services. International Journal Of Contemporary Hospitality Management, 28(12), 2820-2841. doi:10.1108/ IJCHM-04-2015-0214

Liao, S. H., Chen, C. C., \& Hu, D. C. (2018). The Role Of Knowledge Sharing And LMX To Enhance Employee Creativity In Theme Park Work Team: A Case Study Of Taiwan. International Journal Of Contemporary Hospitality Management, 30(5), 2343-2359. doi:10.1108/IJCHM-09-2016-0522

Lin, F. H. (2007). Knowledge Sharing And Firm Innovation Capability: An Empirical Study. International Journal of Manpower, 28(3-4),315-332.doi:10.1108/01437720710755272

Mittal, S., \& Dhar, R. L. (2015). Transformational Leadership And Employee Creativity: Mediating Role Of Creative Self-Efficacy And Moderating Role Of Knowledge Sharing. Management Decision, 53(5), 894-910. doi:10.1108/MD-07-2014-0464

Nguyen, H. M., Nguyen, C., Ngo, T. T., \& Nguyen, L. V. (2019). The Effects Of Job Crafting On Work Engagement And Work Performance: A Study Of Vietnamese Commercial Banks. Journal of Asian Finance, Economics and Business, 6(2), 189201. doi: 10.13106/jafeb.2019.vol6.no2.169

Paais, M., \& Pattiruhu, J. R. (2020). Effect Of Motivation, Leadership, And Organizational Culture On Satisfaction And 
Employee Performance. Journal of Asian Finance, Economics and Business, 7(8), 577-588. doi: 10.13106/jafeb.2020.vol7. no8.577

Patiar, A., \& Wang, Y. (2016). The Effects of Transformational Leadership and Organizational commitment On Hotel Departmental Performance. International Journal Of Contemporary Hospitality Management, 28(3), 586-608. doi:10.1108/IJCHM-01-2014-0050

Padayachee, N. K. D. (2009). The Application And Relevance Of Spiritual Leadership In The JSE Top 40 Companies. Gordon Institute of Business Science. University of Pretoria.

Petrou, P., Demerouti, E., Peeters, M. C. W., Schaufeli, W.B., \& Hetland, J. (2012). Crafting A Job On Adaily Basis: Contextual Correlates And The Link To Work Engagement. Journal of Organizational Behavior, 33(8), 1120-1141. doi:10.1002/ Job. 1783

Petrou, P., Demerouti, E., \& Schaufeli, W. B. (2015). Job Crafting in Changing Organizations: Antecedents and Implications for Exhaustion and Performance. Journal of Occupational Health Psychology, 20(4), 470-487. doi:10.1037/A0039003

Purba, S. (2009). The Influence of Organizational Culture, Intellectual Capital, Innovative Work Behavior to Employee. Journal of Business and Economics, 13(2), 87-103.

Ritala, P., Olander, H., Michailova, S., \& Husted, K. (2015). Knowledge Sharing, Knowledge leaking And Relative Innovation Performance: An Empirical Study. Technovation, $35,22-31$.

Reave, L. (2005). Spiritual Values And Practices Related To Leadership Effectiveness. The Leadership Quarterly, 16(5), 655-687. Doi:10.1016/J.Leaqua.2005.07.003

Rudolph, C. W., Katz, I. M., Lavigne, K. N., \& Zacher, H. (2017). Job Crafting: A Meta-Analysis Ofrelationships With Individual Differences, Job Characteristics, And Work Outcomes. Journal of Vocational Behavior, 102, 112-138. doi:10.1016/J. Jvb.2017.05.008

Sani, A., Soetjipto, B. E., \& Ekowati, V. M. (2016). The Effect Of Spiritual Leadership On Workplace Spirituality, Job Satisfaction And Ihsan Behaviour (A Study On Nurses Of Aisyiah Islamic Hospital In Malang, Indonesia). Journal International Journal of Applied Business and Economic Research, 14(11), 76757688.

Schuckert, M., Kim, T. T., Paek, S., \& Lee, G. (2018). Motivate to Innovate: How Authentic and Transformational Leaders Influence Employees' psychological Capital and Service Innovation behavior. International Journal of Contemporary Hospitality Management, 30(2), 776-796. doi:10.1108/ IJCHM-05-2016-0282

Sekaran, U. (2003). Research Methods For Business A SkillBuilding Approach. Hoboken, NJ: John Wiley \& Sons.

Sengkey, S. B., \& Meiyanto, I. J. K. S. (2016). Transformational Leadership, Organizational Climate To Job Crafting. Gadjah Mada Journal of Psychology, 2(3), 152-161
Slemp, G. R., \& Vella-Brodrick, D. A. (2014). Optimising Employee Mental Health: The Relationship Between Intrinsic Need Satisfaction, Job Crafting, And Employee Well-Being. Journal of Happiness Studies, 15(4), 957-977. doi: 10.1007/ S10902-013-9458-3

Spiegelaere, D. S., Van, G. G., De Witte, H., Niesen, W., \& Van, H. G. (2014). On The Relation Of Job Insecurity, Job Autonomy, Innovative Work Behavior And The Mediating Effect Of Work Engagement. Creativity and Innovation Management, 23(3), 318-330. doi:10.1111/Caim.12079

Stachowicz-Stanusch, A., \& Simha, A. (2013). An Empirical Investigation Of The Effects Of Ethical Climates On Organizational Corruption. Journal of Business Economics and Management, 14(1), 433-446. doi: 10.3846/16111699.2012.744345

Supriyanto, A. S. (2019). Obtaining Factors Affecting Innovative Work Behavior (IWB) Of A Local Bank Employees Under Islamic Leadership: Application Of Partial Least Squares Method. Industrial Engineering \& Management Systems, 18(3), 417-425. doi: 10.7232/Iems.2019.18.3.417

Supriyanto, A. S., Ekowati, V. M. Haris, A., Soetjipto, B. E., Harianto, R., \& Yahya, M. (2020). The Effect of Organizational Citizenship Behavior on Job Satisfaction Mediated with Spiritual Leadership. International Journal of Business and Society, 21(2), 737-748

Supriyanto, A. S., \& Ekowati, V. M. (2020). Spiritual Leadership And Islamic Organisational Citizenship Behaviour: Examining Mediation-Moderated Process. International Journal of Innovation, Creativity and Change. 13(3), 166-185.

Tangaraja, G., Mohd R. R., Ismail, M., \& Abu S. B. (2015). Fostering Knowledge Sharing Behaviour Among Public Sector Managers: A Proposed Model For The Malaysian Public Service. Journal Knowledge Management, 19, 121-140. doi: 10.1108/JKM-11-2014-0449

Tims, M., Bakker, A. B., \& Derks, D. (2012). The Development And Validation Of The Job Crafting Scale. Journal of Vocational Behavior, 80(2), 173-186. doi:10.1016/J.Jvb.2011.05.009

Tuan, L. T. (2017). HR Flexibility and Job Crafting in Public Organizations: The Roles of Knowledge Sharing and Public Service Motivation. Group \& Organization Management, doi: 10.1177/1059601117741818.

Van W. J., Derks, D., \& Bakker, A. B. (2017). The Impact Of Personal Resources And Job Crafting Interventions On Work Engagement And Performance. Human Resource Management, 56(1), 51-67. doi:10.1002/Hrm.21758

Wang, H., Demerouti, E., \& Le Blanc, P. M. (2017). Transformational Leadership, Adaptability, And Job Crafting: The Moderating Role Of Organizational Identification. Journal of Vocational Behavior, 100(June 2017), 185-195. doi:10.1016/J.Jvb.2017.03.009

Wibowo, W. (2016). College Textbook Writing, Its Nature, Formulation, And Ethical Problems. Raja Grafindo Persada. Jakarta. 
Williams, A., Seng, B. R., Hayek, M., Haden, S. P., \& Atinc, G. (2017). Servant Leadership And Followership Creativity: The Influence Of Workplace Spirituality And Political Skill. Leadership \& Organization Development Journal, 38(2),178193. doi: 10.1108/LODJ-02-2015-0019

Woods, S. A., Mustafa, M. J., Anderson, N., \& Sayer, B. (2017). Innovative Work Behavior And Personality Traits: Examining The Moderating Effects Of Organizational Tenure. Journal of Managerial Psychology, 33(1), 29-42. doi:10.1108/JMP-012017-0016

Wang, M., Guo, T., Shang, S., \& Tang, Z. (2019). The Effect Of Spiritual Leadership On Employee Effectiveness: An Intrinsic Motivation Perspective. Frontiers in Psychology, 9, 1-11. doi:10.3389/Fpsyg.2018.02627
Yang, L., Johnson, R. E., Zhang, X., Spector, P. E., \& Xu, S. (2013). Relations Of Interpersonal Unfairness With Counterproductive Work Behavior: The Moderating Role Of Employee selfidentity. Journal of Business and Psychology, 28(2), 189-202. doi:10.1007/S10869-012-9271-8

Yunus, N., Amirishak, N. A., Mustapha, R. M. R., \& Othman, A. K. (2010). Displaying Employees' Organizational Citizenship Behavior At The Workplace: The Impact Of Superior's Emotional Intelligence And Moderating Impact Of LeaderMember Exchange. Vision, 14, 13-23. doi: 10.1108/LODJ-092015-0207

Yusof, J. M., \& Tahir, I. M. (2011). Spirituality Leadership And Job Satisfaction. A Proposed Conceptual Framework. Information Management and Business Review 2(6), 239-245. doi: 10.22610/Imbr.V2i6.903.G903 